\title{
COEXISTENCIA DE COSMOVISIONES EN LA COMUNIDAD EÑEPÁ DE LA BATEA A PARTIR DEL IMPACTO EVANGELIZADOR DE MISIÓN NUEVAS TRIBUS (AMAZONAS VENEZOLANO)
}

\author{
COEXISTENCE OF WORLDVIEWS IN THE EÑEPÁ COMMUNITY OF \\ LA BATEA AFTER THE EVANGELIZATION IMPACT OF NEW TRIBES MISSION \\ (VENEZUELAN AMAZON)
}

\author{
Alessandra Caputo-Jaffe ${ }^{1}$
}

\begin{abstract}
En el siguiente artículo se estudia la coexistencia de cosmovisiones en la comunidad Eñepá de La Batea del Amazonas venezolano, la cual fue evangelizada por Misión Nuevas Tribus alrededor de la década de 1970. Expone la experiencia de trabajo de campo durante tres años de visitas continuas realizadas por la autora entre 2014 y 2016, en las que la realidad de esta población fue poniendo en evidencia la capacidad de resistencia que tiene la cosmovisión Eñepá frente a la imposición cristiana. De esta manera, intenta resaltar cómo el proceso de evangelización implicó por un lado cambios importantes en las prácticas religiosas precedentes, así como en los discursos míticos. Pero por otro lado hubo muchos elementos de las creencias y prácticas culturales Eñepá que pervivieron y que conviven con las creencias y prácticas cristianas, en la medida en que no pertenecen al mismo orden de pensamiento y a la misma cosmovisión.
\end{abstract}

Palabras claves: Eñepá, Amazonas venezolano, evangelización, Misión Nuevas Tribus, perspectivismo, transculturización.

The following work studies the coexistence of worldviews in the Eñepá community of La Batea in the Venezuelan Amazon, which was evangelized by New Tribes Mission around the 1970s. The researcher continually visited this community for three years, between 2014 and 2016. During this period, the reality of this community showed to be a complex coexistence of different worldviews, in which the Eñepá belief-system managed to resist its complete replacement by Christianity. On the one hand, the Evangelization process implied important changes in their own religious practices and mythical discourses, while, on the other, many elements of their beliefs and cultural practices managed to survive, as they did not belong to the same order of thought and worldview as the Christian belief system.

Key words: Eñepá, Venezuelan Amazon, evangelization, New Tribes Mission, Perspectivism, transculturation.

Todo cuanto sé del mundo, incluso lo sabido por ciencia, lo sé a partir de una visión más o de una experiencia del mundo sin la cual nada significarían los símbolos de la ciencia (Merleau-Ponty 1994:8).

Comprender la cosmovisión en comunidades indígenas amazónicas supone un reto particular cuando nos enfrentamos a situaciones donde confluyen el mundo indígena con el mundo "occidental" o "moderno", así como con otras prácticas religiosas, ya que exigen repensar las dinámicas de pervivencia y coexistencia de formas de percibir y entender el mundo distintas en un mismo contexto sociocultural. Es este el caso del siguiente estudio, el cual se centra en un poblado de la sociedad indígena Eñepá, perteneciente al grupo lingüístico caribe del Amazonas venezolano, donde coexisten su propia cosmovisión indígena con la cristiana, adquirida a partir de un proceso de evangelización que comenzó en la década de 1970 y que culminó con una progresiva adaptación a la sociedad criolla (que podemos entender como aquella que funciona según las lógicas políticas, económicas, tecnológicas y culturales de la vida contemporánea venezolana).

Por un lado, la relación con el mundo de la naturaleza y los espíritus así como algunas concepciones básicas de la existencia humana siguen perteneciendo a aquella cosmovisión existente antes de la evangelización, regida según las lógicas del "perspectivismo" y "multinaturalismo" propias de las cosmovisiones amazónicas, que esbozaremos más adelante a partir de los escritos de Viveiros

1 Centro de Estudios Culturales Latinoamericanos, Facultad de Filosofía y Humanidades, Universidad de Chile, Santiago, Chile. alessandra.caputo@gmail.com 
de Castro (2002). Por otro lado, algunos espacios del mundo ritual y de las costumbres cotidianas se han redirigido a una visión cristiana, fundamentada en el conocimiento y la aceptación de la Biblia, la creencia de Dios, así como la diferenciación dicotómica entre los espacios de lo sagrado y de lo profano, del Bien y del Mal.

Específicamente, trabajamos con la comunidad Eñepá de La Batea, ubicada en las riberas del río Suapure del valle de Colorado, en la frontera del Amazonas con la Guayana venezolana (municipio Cedeño, estado Bolívar), que sirve como un buen ejemplo para retratar la pervivencia de la cosmovisión amazónica en las sociedades evangelizadas. Este poblado fue fundado hace unos 40 años por familias que procedían de la comunidad de Colorado, que había llegado a un punto de saturación demográfica. Se trata por ello de un lugar apropiado para el estudio, ya que cuenta con una población relativamente reducida (150 personas, aproximadamente) ${ }^{1}$.

En este caso nos enfocaremos principalmente en la influencia evangelizadora, aunque esto no quiera decir que el impacto "criollizante" no sea relevante. De hecho, los procesos de cambio hoy se deben principalmente a la influencia que tiene la cultura venezolana y la política respecto de estas comunidades. Además, en estos últimos años varias misiones católicas han continuado el contacto con las comunidades indígenas de la zona; no obstante, su labor solo ha sido parcialmente evangelizadora, porque se ha centrado más bien en instaurar centros de educación. Así, los ritos cristianos Eñepá se mantienen sustancialmente evangélicos.

Sin embargo, el mayor punto de interés que presenta esta comunidad es que se ha mantenido sorprendentemente aislada de la influencia del mundo criollo a pesar de que poblados como Morichalito y Los Pijiguaos se encuentren a unos dos kilómetros de distancia. Solo hace apenas unos 20 años los Eñepá comenzaron a adoptar las costumbres y modos de vida provenientes del contacto con el mundo criollo y las políticas de Estado nacionales, como la introducción del sistema de educación, salud, vestimenta y tecnologías "occidentales" (teléfonos celulares, motocicletas, radios, etc.).

Previo a estos cambios, las poblaciones Eñepá ubicadas en el valle de Colorado, donde se ubica La Batea, fueron evangelizadas por la organización norteamericana Misión Nuevas Tribus (MNT). Este proceso comenzó en 1972 y duró unas tres décadas, acarreando radicales cambios en su sistema de creencias (Corradini 1981; Villalón 1979). A pesar de que MNT fuera expulsada del país en 2005 por decreto del gobierno, las comunidades afectadas ya habían adoptado nuevas formas de vida y creencias que, en apariencia, parecían haber dejado atrás las viejas tradiciones ancestrales Eñepá.

La evangelización de los Eñepá es solo uno de los tantos casos de evangelización por MNT que se han dado en numerosas poblaciones indígenas de América. Un reciente estudio publicado por Vilaça (2016) retrata este mismo fenómeno entre la sociedad Wari' del Amazonas brasileño. Basado en un trabajo de varias décadas, representa un aporte fundamental para la comprensión de este complejo proceso de transformación, apropiación y adaptación de nuevas formas de comprender la religiosidad y las relaciones del individuo con su entorno. Sobre todo, invita a contemplar bajo una nueva luz el fenómeno de evangelización de las poblaciones indígenas a partir de la segunda mitad del siglo XX, ya que no solo se centra en los cambios, sino también en las permanencias de las formas de pensar preexistentes, que se rigen bajo lógicas que cubren otros ámbitos, como la relación trascendental y extrasensorial con el mundo de la naturaleza y las entidades sobrenaturales, que no contradicen la cosmovisión cristiana.

Cabe remarcar que el proceso de evangelización entre los Eñepá ha sido extensamente investigado por autores como Henley (1982), Corradini (1981) y Villalón (1979), quienes pudieron describir las ideologías e idiosincrasias introducidas por MNT, así como la aceptación e incorporación de los cultos evangélicos en estas comunidades. Sin embargo, han pasado varias décadas desde que estos escritos fueron publicados y queremos ofrecer una actualización del estado de la cuestión de la cosmovisión Eñepá tras la retirada de estas entidades misioneras del país en 2005. Este trabajo pretende servir también como complemento a la información etnográfica disponible acerca de los Eñepá de las décadas de 1950 hasta 1990 (de autores como Antolinez 1952; Corradini 1981, 2002; Dumont 1971, 1972; Henley 1982, 2011; Mattei-Muller 1992; Villalón 1979; Wilbert 1959). Asimismo, se espera contrastar con investigaciones más recientes llevadas a cabo entre la comunidad de San José de Kayamá (Quatra 2009) en las que aún existen prácticas chamánicas y donde pervive claramente la ontología amazónica propia de los Eñepá, sin aparente influencia del cristianismo.

Con ello, esperamos elucidar en qué medida la evangelización ha supuesto por un lado un cambio en la forma de concebir los relatos míticos, 
rituales y costumbres de la vida cotidiana de estas comunidades. Pero por otro señalaremos en qué medida la imposición de la visión de mundo cristiana no abarca los mismos ámbitos que contiene la cosmovisión Eñepá preevangélica, dejando por ello pervivir muchos aspectos de esta. Así, partiendo de enfoques como el de Vilaça (2016), esperamos escudriñar las dinámicas de pervivencia de las creencias y visiones de mundo que forman parte de las cosmovisiones amazónicas y que lograron resistir a los cambios de creencias y costumbres, precisamente por pertenecer a otro orden de pensamiento. Tanto en el reciente estudio de Vilaça como en nuestro caso específico, pudimos comprobar que la evangelización no produjo un cambio tan radical como apuntan las permutaciones de ciertas costumbres rituales y cotidianas. Al contrario, se sugiere que a pesar de las intenciones por parte de MNT de erradicar las costumbres indígenas, la evangelización implicó más bien un proceso de apropiación y adaptación de un nuevo sistema de creencias, sin ser un proceso pasivo ni definitivo en las sociedades afectadas.

\section{Breve Contexto Etnográfico Eñepá}

Los Eñepá pertenecen a la rama lingüística caribe que habita en las regiones occidentales del municipio Cedeño del estado Bolívar en Venezuela. Su población actual rodea los 4.600 habitantes (censo 20112), que se distribuyen en varias poblaciones entre el río Cuchivero al este, el río Suapure al oeste, el Caño Iguana al sur y el Orinoco al norte (Figura 1). Sus formas de subsistencia aún se basan principalmente en la siembra del conuco (roza y quema), la caza y la pesca con barbasco (Lonchocarpus nicou), bejuco utilizado desde época precolombina cuyas toxinas narcotizan a los pescados. También han incorporado en algunos poblados la cría de ganados y la venta de productos como verduras, sarrapia y artesanías al mercado criollo.

Existen importantes diferencias entre los Eñepá ubicados a lo largo del río Cuchivero, en Caño Iguana o Kayamá por un lado y el Suapure o valle de Colorado por otro. Estas se hacen particularmente sensibles en el lenguaje, que varía de manera considerable de población en población; pero sobre todo, se deben a que las regiones del Cuchivero y Kayamá no fueron evangelizadas, lo que sí sucedió en las zonas del Suapure y el valle de Colorado (donde centraremos este estudio).

A nivel etnohistórico, los Eñepá son relativamente desconocidos y su mención es casi inexistente en las crónicas coloniales: si bien estas se remontan a los escritos de Gumilla (1745) y luego Gilij (1965 [1782]), quienes los mencionan bajo el nombre Oyé (denominación que les daban los Ye'kuana) (Villalón 2007), solo especificaban que habitaban las regiones del Orinoco Medio. Son conocidos tradicionalmente por los criollos como los Panare, término acuñado por primera vez en el Atlas de Codazzi de 1841 (Villalón 2007:17), cuya raíz proviene posiblemente del idioma tamanaco (también lengua caribe, ya extinta) "panari", que significa "amigo" (Gillij 1965 Tomo I:136). "Eñepá", en cambio, es la autodenominación de este pueblo.

No existen estudios extensivos de los Eñepá hasta la década de los sesenta, cuando comienzan a hacerse etnografías más completas, como el caso de Dumont (1971, 1972 [1962]), quien presenta sin embargo numerosas discrepancias con las demás etnografías, sobre todo en temas que conciernen la mitología y la cosmovisión (por ejemplo, según él el Creador es "Manatachi”, cuando los demás estudios confirman que es Mareoka). Autores como Henley (1978, 1982, 2011), Mattei-Muller (1992, 1994) y Mattei-Muller y Henley (1987) pudieron recolectar mejores datos acerca de su cosmovisión, estructura social y cultura material, y realizar incluso un extenso diccionario eñepá-español (Mattei-Muller 1994). En su trabajo junto con el chamán Yorokó, Mattei-Muller (1992) logró recolectar importantes elementos de su cosmovisión, dejando entender el continuиm multinaturalista presente en esta cultura. Existen además numerosos registros visuales de sus costumbres rituales y cotidianas previas a la evangelización, que fueron realizadas entre la década de los setenta y los noventa (Corradini 1981; Dumont y Nairn 19703; Henley y Drion 19874; Mattei-Muller 1992, 1994; Vallés 1992). A partir de fines de la década de los setenta comenzarían las primeras denuncias contra MNT en la zona, así como de los repentinos cambios que comenzaron a apreciarse en estas sociedades (Corradini 2002; Monsony et al. 1981; Villalón 1979).

\section{Misión Nuevas Tribus entre los Eñepá}

Fundada en 1942 por Paul Flemming, Misión Nuevas Tribus (MNT) expande su empresa misionera en su intento de hacer llegar el Evangelio hasta las regiones más remotas del mundo (http://espanol.ntm. org/). La misión protestante está basada actualmente en el Estado de Florida en los Estados Unidos de América, y trabajó en asociación al Instituto Lingüístico de 


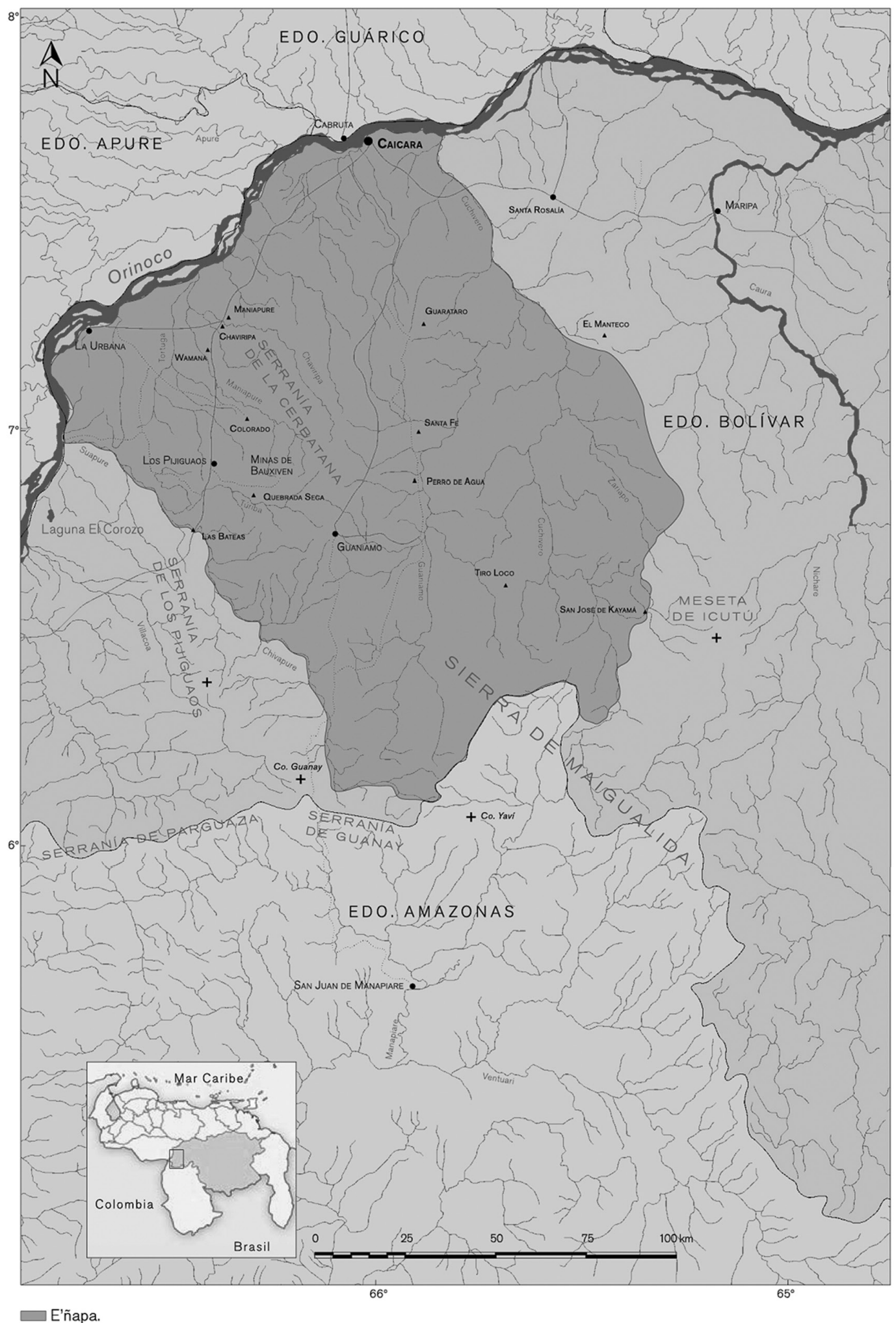

Figura 1. Mapa de las regiones Eñepá, estado Bolívar, Venezuela (extraído de Villalón 2007). Map of the Eñepá Regions, Bolívar State, Venezuela (from Villalón 2007). 
Verano, con el que realizaban programas para el aprendizaje y traducción de la Biblia en las lenguas vernáculas de los indígenas. A nivel teológico, los misioneros de Nuevas Tribus pertenecen a la rama Independiente Fundamentalista (Vilaça 2015:202), cuya doctrina es dispencionalista, basada en la interpretación literal de la Biblia5. Su alcance global se genera por donaciones de iglesias independientes en Estados Unidos, con las que envían a terreno a familias misioneras, previamente entrenadas en los "centros de entrenamiento" de la organización (Missionary Training Center), donde aprenden a "sembrar" el Evangelio entre sociedades "no alcanzadas" por el cristianismo (http://espanol.ntm.org/).

Misión Nuevas Tribus entra oficialmente a Venezuela en 1946, obteniendo en los años cincuenta un permiso indefinido del gobierno de Marcos Pérez Jiménez para realizar sus trabajos misioneros, como respuesta al interés de este último en tomar control político del territorio Federal Amazonas (actualmente estado Amazonas) que había sido poco incursionado hasta la fecha (Luzardo 1981). Sus fundadores fueron Pablo Dye y Jaime Bou, quienes para la década de los setenta dirigían esta misión como una Asociación Civil sin fines de lucro. A pesar de tener permiso para realizar sus labores misioneras únicamente dentro del estado Federal Amazonas, MNT fue expandiéndose poco a poco entre diversas comunidades indígenas de otras regiones, incluyendo el estado Bolívar, donde se encuentran los Eñepá.

En el valle de Colorado y el río Suapure, donde se ubica La Batea, llegaron distintas familias norteamericanas a evangelizar poblaciones como Túriba, Colorado, Guamal, entre otras. A La Batea no llegaron a asentarse los norteamericanos, sino que fueron evangelizados por los aprendices Eñepá, quienes continuaron la labor misionera incluso después de que MNT fuera expulsada del país.

La táctica evangelizadora aplicada por MNT coincide en ciertos aspectos con los procesos evangelizadores llevados a cabo en esta región durante la época Colonial, aunque tiene sus propias características diferenciadoras. Durante la Colonia, los misioneros que se adentraron en el Orinoco Medio, como los capuchinos y los jesuitas (entre ellos Gumilla y Gilij, siglo XVIII) fueron comisionados para realizar una nueva fase del proceso conquistador, el cual había fracasado militarmente (Civrieux 1976). Con este acercamiento más "pacífico", los misioneros lograron ganar la confianza de algunas comunidades y disuadirlos a cambiarse de culto, así como a pasar a vivir en las reducciones. Solo por medio de la religión las temidas "tribus" Caribe pudieron ser relativamente controladas y reducidas en Misiones donde poco a poco fueron criollizándose. Las herramientas básicas de evangelización del Orinoco (compartidas con MNT) fueron la creación de lazos de confianza, relaciones de dependencia por bienes como herramientas, alimentos, medicinas y otros; y en muchos casos las tácticas coercitivas con las que los evangelizadores amenazaban a los indígenas para que se convirtieran (por ejemplo, les inculcaban miedo al decirles que si no se bautizaban les esperaba un destino infernal después de su muerte).

Ya en el período republicano y contemporáneo las misiones católicas y las políticas de Estado que procuraron llevar la "modernización" a las comunidades indígenas, lo hicieron mediante la introducción del castellano como el idioma que simbolizaría el paso hacia el "progreso" y la "civilización". Como fue comentado anteriormente, las misiones católicas que continúan ejerciendo hoy una labor misionera en estas regiones indígenas se centran sobre todo en el ámbito de la educación y en su inserción en la sociedad "criolla".

En cambio, una de las particularidades de misiones como MNT consiste en que ellos optaron por insertarse en el mundo indígena adoptando el idioma vernáculo como forma principal de comunicación; y sobre todo, traduciendo el Evangelio a estas lenguas.

Por lo general continuaron una vida bastante apartada del mundo criollo, en parte debido a que los evangélicos alimentaban el recelo de los Eñepá hacia los criollos, con quienes habían tenido múltiples conflictos a lo largo de la historia, posicionándose en cambio como verdaderos "amigos" de los indígenas.

El resultado, sin embargo, fue sumamente perjudicial según el gremio antropológico (Monsonyi et al. 1981), quienes desde la década de 1970 comenzaron a denunciar las labores misioneras y exigir leyes que protegieran la libertad de culto y diversidad cultural. Cabe destacar que hasta la Constitución de 19996 regía en Venezuela la Ley de Misiones de 19157, en la cual los pueblos indígenas eran considerados "no civilizados" y daba plenos derechos a los misioneros de disponer de ellos y encargarse de su proceso "civilizatorio".

Gran parte de las denuncias en contra de MNT criticaban así las tácticas extremadamente coercitivas para lograr la conversión de los indígenas (incluso más intransigentes que las coloniales), en las que, 
aparte de generar relaciones de dependencia material y espiritual con los indígenas, los manipulaban y amenazaban mediante escritos que distorsionaban el contenido original del Evangelio. Así lo leemos en uno de sus diferentes opúsculos en el idioma eñepá que suponían enseñar el cristianismo, Pirentatope Ariyopä (Aprendiendo Dios 1975):

Dios estaba bravo con los Panare.

Dios quería matarlos porque ellos eran malos

Todos los Panare son malos. Sois malvados.

Todos sois ladrones, embusteros, cojen [sic] la mujer del prójimo.

Sois peleadores. Dios no quiere a los malvados.

Sois todos malos -toditos-

(así) habló Dios.

[...]

Dios los quemará a todos. Quemará también todos los animales.

Quemará también la tierra, el cielo, todo absolutamente.

Quemará también los mismos Panare.

Dios exterminará los Panare, echándolos

al fuego [...] (extraído de y traducido por

Corradini 1981:109).

Igualmente, leemos cómo los evangélicos condenaban abiertamente las prácticas funerarias y rituales de estas comunidades, adjudicándolas diabólicas o satánicas (Corradini 1981:113). Con la intrusión de MNT se establecieron así diversas proscripciones, como el cese de las prácticas rituales, la ingesta de bebidas alcohólicas tradicionales a base de fermento de yuca (el cachiri); e incluso algunas prácticas básicas como la siembra de la yuca, ya que con ella se elaboraba el cachiri (1979); en fin, cualquier atisbo que pudiera remitir al sistema de creencias anterior. En resumen, se trató de un proceso bastante efectivo que incluía, por un lado, la relación amistosa, la confianza y las ofrendas; mas por otro lado suponía la inculcación del miedo a desobedecer la "voluntad de Dios" y el tabú de perpetuar las creencias pasadas.

\section{Trabajo de Campo y Reajuste de Perspectivas}

El trabajo de campo en la comunidad Eñepá de La Batea tuvo inicio en 2014, con la meta de recuperar algunos mitos ancestrales que habían sido recogidos fragmentariamente por autores como Henley (1982, 2011), Mattei-Muller (1992) y Corradini (2002). A partir de entonces realicé varias visitas de dos semanas cada una, durante tres años consecutivos, que reunieron en total unos tres meses de trabajo de campo. En estos tuve la oportunidad de entrevistar a gran parte de la población, incluyendo el cacique Roberto Moreno y el capitán Vicente Flores, cuya figura de poder es más reciente y sirve principalmente de intermediaria con las entidades gubernamentales. Asimismo, entrevistamos a su hermano José Flores, encargado de la atención primaria de salud ${ }^{8}$, y algunos ancianos como José Moreno, padre del actual cacique. También tuve la oportunidad de entablar conversaciones con varias mujeres, entre ellas ancianas, como Teresa Moreno (madre del actual cacique) y Rosa Flores (madre del capitán); adultas, como Carolina Requena (hija del difunto cacique y esposa de Juan Requena); jóvenes veinteañeros, como Marisol (hija de Carolina y Juan Requena) y su esposo Timoteo Flores, y algunos adolescentes ${ }^{9}$. Cabe destacar que la mayoría de las entrevistas a las personas más ancianas se realizaron por medio de traductores y los informantes pidieron explícitamente no ser registrados, por lo que no serán citados textualmente en este trabajo.

En particular, conté con el apoyo de Juan Requena y su familia, quien me adoptó como su hija. Juan Requena es uno de los pastores evangélicos de la comunidad y al llegar por primera vez a $\mathrm{La}$ Batea me fue asignado como "guía" por el consejo de hombres del pueblo, por lo que accedió a que registrara nuestras conversaciones con audio. Es quien me ha explicado con mejor detalle en qué consiste su creencia cristiana, y a su vez, quien me ha enseñado los conocimientos de su naturaleza y la relación de esta con el mundo espiritual tradicional Eñepá; resultando ser así la prueba más clara de coexistencia de dos cosmovisiones.

A partir de las recomendaciones y observaciones de antropólogos y trabajos previos que denuncian los estragos producidos por las misiones y las políticas modernizadoras desde la década de 1970 (Corradini 1981; Villalón 1979; entre otros), llegué a mi primera estancia en La Batea con la idea de que la evangelización había generado una especie de tabula rasa, imponiendo una nueva manera de comprender el mundo a partir del cristianismo que renunciaba a todo tipo de reminiscencia cultural que los uniera a sus tradiciones pasadas. Además, a partir de la lectura de las propias experiencias de 
los misioneros de MNT, esta parecía ser su intención (Price y Price 1972, 1977, http://espanol.ntm.org/10).

Durante la primera experiencia de campo se vieron en parte reforzados estos prejuicios por distintos motivos: el primero y el más contundente, era el infranqueable mutismo que caracterizaba a los miembros de esta comunidad. Toda pregunta que tuviese que ver con las costumbres y creencias previas a la evangelización era respondida con una negación o silencio. Hablar del pasado parecía una suerte de tabú o, al menos, comprendía una actitud muy descortés de parte mía por indagar acerca de intimidades tan bien guardadas. Además estaba terminantemente prohibido grabar, fotografiar o registrar en audio a las personas en la comunidad, lo cual resultó sorprendente, ya que en trabajos previos a la evangelización esto no era un problema.

En segundo lugar, esta comunidad se caracterizaba por ser particularmente austera en su cultura material; pasados unos veinte años desde los últimos trabajos de campo realizados en la zona, apenas encontraba aquellas insignias culturales que habían sido descritas antaño, como la presencia de pintura corporal, la amplia variedad de objetos elaborados en cestería, incluso aquella producida para la venta al turismo. Asimismo, no encontré ya ningún vestigio de los rituales públicos, como el katyayïnto o "puesta del guayuco" de los varones. Si bien pude observar que algunos ancianos conservaban aún instrumentos musicales tradicionales, no quisieron mostrármelos y explicaron que habían olvidado cómo tocarlos. En general, hablar acerca del tema de las creencias religiosas causa aún cierta incomodidad: suelen responder rápidamente que son evangélicos y que no saben o no recuerdan nada de las creencias del pasado ${ }^{11}$.

En cambio, en medio del pueblo se erigía una pequeña choza de bahareque en cuya puerta estaban inscritas en castellano las palabras "Iglesia Evangélica Comunidad Las Bateas"12. (Figura 2). En el interior de esta casa se veían algunos bancos y en el fondo una suerte de podio donde relucía un piano eléctrico y una guitarra eléctrica tipo Fender. Sin embargo, en las sucesivas estadías en La Batea fue haciéndose evidente que algunos elementos que inicialmente interpretaba como consecuencias de la evangelización, eran en realidad parte del carácter cultural de los Eñepá.

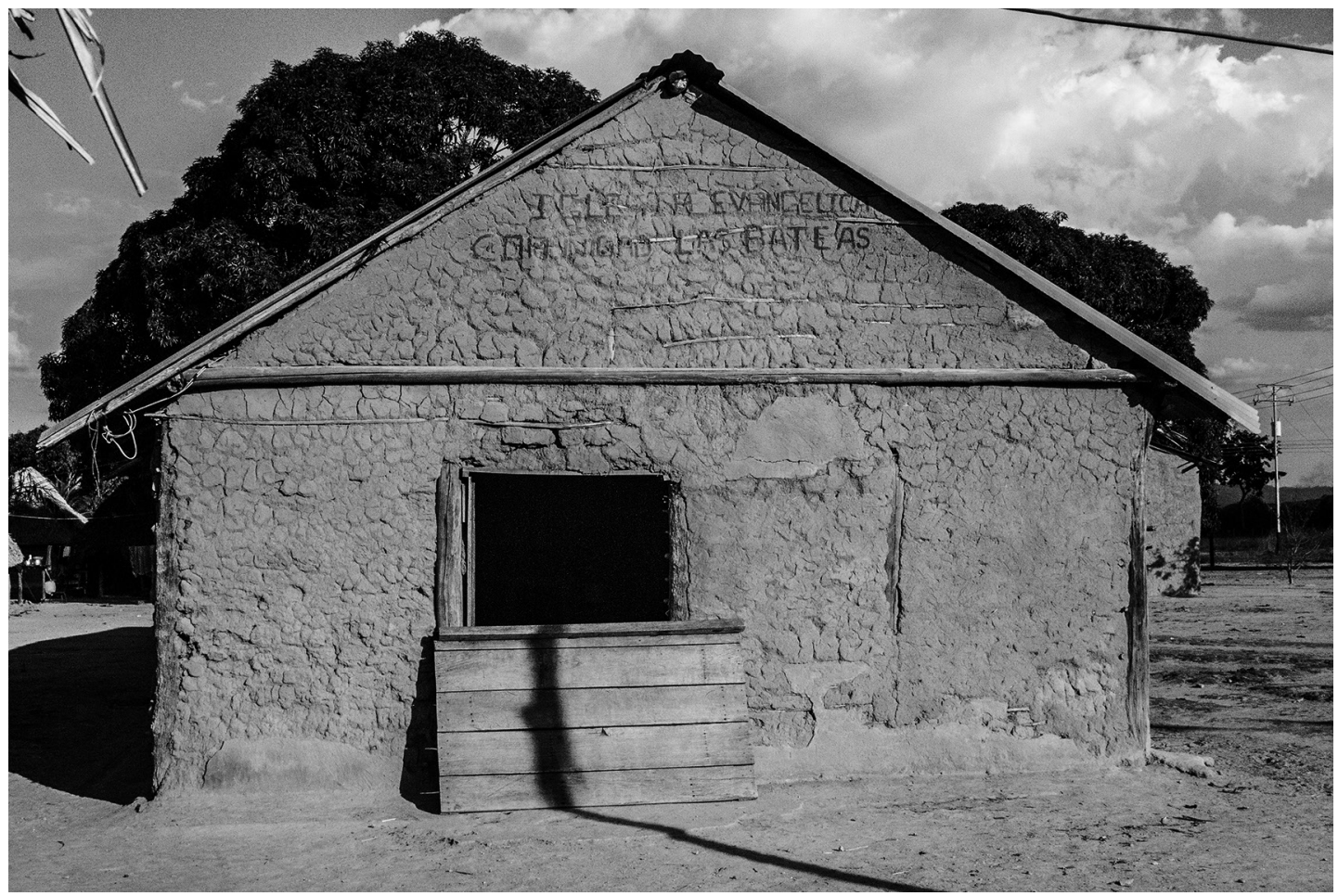

Figura 2. Iglesia evangélica de La Batea (fotografía de la autora).

Evangelical Church of La Batea (photography by the author). 


\section{Cosmovisiones Entretejidas}

La sociedad Eñepá se inscribe dentro de la cosmovisión amazónica identificada por Viveiros de Castro (2002) bajo el término de "perspectivismo" y "multinaturalismo". Ambos conceptos han servido para identificar la especificidad del pensamiento amazónico, cuya premisa parte de la coexistencia e interconexiones entre los humanos, los animales ${ }^{13}$ y los espíritus o seres míticos. Cada uno se percibe como una cultura o una forma de humanidad en sí; se igualan a un nivel "espiritual" -o mejor dicho invisible-, pero se diferencian a nivel natural o físico. Esta diferenciación se fundamenta en una relación de perspectivas: por ejemplo, el jaguar ve al danto como una presa mientras que el danto ve al jaguar como un predador, etc. De la misma manera, en condiciones "normales" 14 , el animal predador o las entidades sobrenaturales ven al hombre como presa (Viveiros de Castro 2002:350). Sin embargo, dentro de las prácticas chamánicas, si el hombre se decora por ejemplo con las "pinturas corporales" del jaguar o un ser sobrenatural, haciéndose pasar por este, podrá "engañarlo" e interactuar con él en dicho plano "espiritual".

Esta idea conduce al pensamiento multinaturalista, según el cual el mundo sobrenatural o "invisible" se percibe como un continuum mientras que el mundo natural o físico-tangible conforma el espacio diferenciador y múltiple. Así, cada especie percibe el mundo de manera análoga, es decir, como una cultura en sí, la que, sin embargo, es invisible a los ojos de quien no pertenece a ella (al menos en un estado "normal" o no chamánico):

\section{[...] los animales utilizan las mismas categorías y valores que los humanos: sus mundos, como el nuestro, giran en torno a la caza y la pesca, la cocina y las bebidas fermentadas, los primeros cruces y la guerra, los ritos de iniciación, los chamanes, jefes, espíritus, etc. (Viveiros de Castro 2002:378, trad. de la autora).}

Si bien no he tenido aún la oportunidad de escuchar los relatos míticos directamente de los informantes ${ }^{15}$, he podido corroborar que el pensamiento amazónico se reconoce a partir de los mitos recogidos en etnografías anteriores. Según estas recopilaciones los primeros Eñepá surgieron de una gran roca por voluntad del demiurgo, Mareoka, en las montañas del Cuchivero (Corradini 2002; Henley 1982, 2011; Mattei-Muller 1992). A partir de los Primeros Hombres Mareoka comenzó a "mezclar" y "metamorfosear" los primeros animales. Uno de ellos fue el mono araguato (E: ko'tá, L: Alouatta), creado a partir de los primeros Eñepá (Mattei-Muller 1992) cuando estos bailaban en una fiesta pintados con onoto (E: waché, L: Bixa orellana). Por el contrario, leemos que los monos capuchinos (E: arkon, L: Cebus olivaceus) surgieron de los criollos y por ello se caracterizan por ser más desorganizados y bulliciosos (Mattei-Muller 1992). Asimismo, las plantas también pueden haber sido "metamorfoseadas" de algún humano o animal en Tiempos Primordiales, como por ejemplo la ceiba (E: $m a ' k a ́)$, que surge de una mujer embarazada (Mattei-Muller 1992). La creación de los Eñepá parte por tanto de los humanos en un continuum de procesos de metamorfosis hacia las demás especies, que comparten ciertas características con su estado originario.

A partir de la llegada de MNT los conocimientos chamánicos, así como los relatos míticos en torno a la creación por Mareoka y otros héroes culturales, fueron sustituidos por el Evangelio. Sobre todo, las costumbres de vida y las prácticas que iban en contra de aquellas que inculcaban los misioneros fueron aplacadas; y así, los chamanes y sus conocimientos fueron desplazados a tal punto de que ya no los encontramos por estas regiones (sí los hay, en cambio, en poblaciones más apartadas como Kayamá). Con su ausencia dejarían de existir así los principales depositarios y conocedores de los mitos y sabidurías ancestrales. Las prácticas chamánicas desaparecieron por tanto de poblados como La Batea, donde todos los habitantes se consideran evangélicos: así me lo han explicado reiteradas veces tanto el cacique Roberto Moreno como el capitán Vicente Flores, el pastor Juan Requena y todas las personas que he logrado entrevistar. Lo cierto es que la presión social en esta comunidad es importante y si hubiera alguien que no se considerara evangélico no me lo diría, ya que sufriría el oprobio del poblado.

Existe entre los Eñepá de La Batea la creencia de un Dios omnipotente, el Espíritu Santo y Jesucristo, y cuando uno pregunta acerca de la Creación del mundo, replican citando el Génesis. La adopción de la religión cristiana responde estrictamente a la creencia evangélica-protestante, ya que deja completamente por fuera la imagen de santos o de la Virgen, y se fundamenta en la interpretación de 
la Biblia. Asimismo, en sus prácticas se evidencia una ausencia absoluta de imágenes sagradas: no hay ni efigies de ningún tipo, ni cruces en la iglesia u otras partes. Tenía sentido pensar que esta carencia absoluta de elementos simbólicos visuales se debía a la catequización evangélica, que sigue las líneas puritanas del protestantismo y que evita por lo general cualquier clase de iconografía o simbología.

En todo caso, la versión cristiana era la única que me permitieron conocer en La Batea. Sin embargo, poco a poco, en las conversaciones con los informantes fueron aflorando otras realidades que permitieron revelar una cosmovisión distinta.

Así, cuando pregunto ahora si a los Eñepá los creó Mareoka, a veces me responden que sí, o dicen que eso es lo que creían antes. Mareoka no fue sustituido por la imagen de Dios (que en eñepá es llamado Riyóc) o de Jesucristo, sino que parece ser un dios que quedó desplazado y del cual prefieren no hablar con forasteros. Sin embargo, no parece ser una contradicción la coexistencia de distintas creencias religiosas. Mareoka, si bien ya no es considerado el Creador del mundo, sigue formando parte del origen de los Eñepá.

La coexistencia de una cosmovisión amazónica con la cristiana ha podido ser corroborada a partir de las conversaciones con mi guía principal, Juan Requena y su esposa Carolina, así como con uno de los hombres más ancianos del poblado, José Moreno (2016). Ellos me explicaron que algunas plantas y animales poseen ichën o "dueños" (término utilizado por los informantes en castellano), una identidad invisible y sobrenatural que los domina y con quienes los chamanes establecían contacto. Asimismo, corroboraron la existencia de los inyö o "espíritus del bosque" (término utilizado por los informantes en castellano) a quienes hay que respetar cuando se les encuentra en los bosques y llamar por su nombre "humano" (J. Moreno, com. personal 2016).

De la misma manera, los conocimientos de la naturaleza y la interacción de los Eñepá con esta no parecen haber cambiado mucho desde antes de la evangelización. Eso lo pude comprobar en diversas excursiones en la selva con Juan Requena, quien me mostró algunos principios de cómo entienden ellos su entorno natural, lo cual resulta particularmente significativo teniendo en cuenta que él es uno de los pastores evangélicos de la comunidad. Algunos lugares son peligrosos porque ahí moran los ichën (“dueños") y los inyö ("espíritus del bosque"): en una de nuestras caminatas por la selva me picó una araña venenosa, hecho que Juan Requena explicó indicando que el "dueño" de esta zona (llamada Caño Piña) era "malo" y no deseaba dejarnos entrar en su morada (J. Requena, com. personal 2016).

Más adelante, pude comparar los espíritus mencionados por Juan Requena y su familia con aquellos registrados antes de la evangelización por Mattei-Muller (1992), y coincidieron en su totalidad. Relatan Juan Requena y su esposa Carolina (com. personal 2016) que ellos se han encontrado de camino a su conuco con el espíritu de Amana ${ }^{16}$, una enorme serpiente mitad coral, mitad anaconda, que antiguamente fue un chamán llamado Mañän, y que fue convertido por Mareoka en espíritu. Su "soplo" es el arcoíris, visible cuando él está enojado. Cuentan que cuando se le encuentra en el bosque hay que hablarle "bonito" para que no se enoje y permita el paso. Sobre todo, hay que llamarlo por su nombre humano, Mañän, y nunca dirigirse a él por su nombre en estado de serpiente (Amana), porque se enfurece. Esto coincide con las nociones perspectivistas comentadas anteriormente, según las cuales existe a nivel espiritual una identificación entre los Seres como "iguales"; y por eso el espíritu espera que lo llamen por su nombre humano, ya que solo en apariencia (en el mundo físico) este tiene la forma de una serpiente.

La mayoría de los espíritus suelen ser peligrosos e incluso mortales para los seres humanos: por ejemplo, los Eñare toman la forma de mujeres y engañan a los hombres para perderlos y raptarlos en el bosque, cuentan los informantes que incluso algunas mujeres Eñepa pueden convertirse en estos espíritus. Otros tienen forma de animales, como el Waseiko, cuya forma habitual es la de un "tigre", pero puede cambiar en forma de cualquier otro animal. La mayoría de estos seres habitan el bosque y la sabana, aunque algunos como los Kowarekañe viven también en los pueblos y solo los chamanes pueden verlos. Los Asa'me son gemelos (asa quiere decir dos en eñepá) pequeños, tienen el pelo largo y suelen ser muy "bravos". Los Ipumpa, en cambio, no tienen forma ni humana ni animal, sino parecen piedras con caras y cabellos largos, que ruedan y saltan por la sabana haciendo muecas. Si bien parecen inofensivos suelen asustar al caminante que pasa por sus moradas.

Lo mismo se puede decir de los ichën, los dueños de las plantas, los animales y los lugares: a veces pueden ser peligrosos y otras veces inofensivos. 
Normalmente se "ven" en el bosque bajo la forma de algún animal o de un humano, como el Tënawayïm, el dueño de los ríos, que es "bonito como un gato o un perrito" (Carolina y Marisol Requena, com. personal 2016), es inofensivo y se encarga de que el río no se seque. Muchos de los espíritus mencionados anteriormente son a su vez "dueños" de plantas, lugares o animales: por ejemplo, Amana es dueño del tirite (L: Ischmosiphom obliquiformis Loes, E: mananké), las plantas con las que se tejen las cestas del tipo wapa (cestas planas y redondas). Es peligroso cortarlas sin su permiso, ya que puede atacar con sus flechas (versión contrastada con Mattei-Muller y Henley 1978:30). Como fue mencionado anteriormente, ciertas áreas geográficas también pueden tener su "dueño" como por ejemplo la laguna de "Piña", ubicada a unos kilómetros hacia las montañas desde La Batea, cuyo dueño es un "caimán".

Durante nuestras conversaciones, Juan y Carolina Requena (com. personal 2016) me explicaron que al igual que las personas, hay animales que tienen espíritu (inyö). Sin embargo, las plantas no tienen, sino que pueden tener "dueños", que por lo general suelen ser espíritus de animales. Así, no solo Amana es dueño de una de las plantas con las que se teje, sino que el jaguar (akärä) es el dueño de la ceiba (maká), que antaño era un árbol sagrado (MatteiMuller 1992). Como podemos comprobar por medio del estudio de Quatra (2009:73-74), los chamanes suelen hacer infusiones de plantas para atraer a los animales que son sus dueños. Esto pareciera guardar relación con el hecho de que frecuentemente los nombres de las plantas responden a "características" de animales, como por ejemplo, el Kootapananyo, traducible como "árbol de la oreja del araguato" (Leguminose o Fabaceae: Machaerium sp.) o el panketyan, que significaría "hoja de raya" (nombre científico no identificado).

La existencia de "dueños" en la selva no parece interferir con la idea de un orden de creación cristiano. En las conversaciones con Juan Requena (com. personal 2014, 2016) pudimos entender que Dios, que en este caso podía ser intercambiable por Mareoka, creó la naturaleza y todas las formas de relación entre la naturaleza, el hombre y lo sobrenatural. Nuestro informante pasaba de una narrativa cristiana a la Eñepá sin ningún conflicto o contradicción: mientras nos hablaba de las cuevas que tienen pintura rupestre a unos kilómetros de La Batea, explicaba cómo a Dios le gustaba ese lugar y lo había creado porque era "bonito" y "bueno". Existen en cambio otros lugares "feos" y peligrosos, donde los dueños son del "diablo" [sic] (Juan Requena com. personal 2014).

Podemos observar en este apartado cómo, por un lado, la creencia cristiana se manifiesta mediante la absorción de los relatos bíblicos como nuevos discursos y conocimientos míticos, pero que estos no interfieren por otro lado con la relación preexistente que tienen los Eñepá con la naturaleza y la creencia en otro tipo de entidades sobrenaturales, que no son discutidas o mencionadas dentro del discurso cristiano. La coexistencia entre la cosmovisión Eñepá y la cristiana no se da por sustitución de algunos elementos por otro, sino por alternancia, intercambio y simultaneidad de facultades de las entidades divinas: en muchas cosas Dios cumple los roles de Mareoka; asimismo, los dueños de las plantas, animales y lugares existen independientemente de la existencia de Dios y, dependiendo de sus facultades (peligroso/seguro, feo/bonito), pueden ser asociados a lo Divino o a lo Diabólico.

\section{Prácticas Cotidianas y Ritualidad:} Discontinuidades, Sustituciones y Alternancias

Con el cristianismo se impone, eso sí, una nueva dimensión moral y dicotómica entre lo bueno y lo malo, que antes no existía como tal. Como explica nuestro informante, Juan Requena, antes los Eñepá eran "malos" o "feos" (en eñepá se dice ta'me, que también quiere decir "prohibido", Mattei-Muller com. personal 2014) cuando bebían cachiri y se peleaban por las mujeres, la cacería y los bienes; pero ahora son "buenos" y "no hay más problemas" porque Dios les enseñó a no pelear, a portarse bien, a tener solo una mujer, a orar (Juan Requena, com. personal 2016). Con esto se impone por tanto una ontología cristiana, fundamentada en una dicotomía entre lo sagrado y lo profano, el bien y el mal, la noción del pecado y de la escatología (la idea del "destino final" de la humanidad).

Es cierto que, al igual que los conocimientos chamánicos y los mitos de creación, los principales rituales de esta comunidad también serían aplacados durante la evangelización. Algunos de estos serían el phapëto (el ritual funerario) y las costumbres matrimoniales. Quedó prohibida la poligamia, práctica frecuente sobre todo entre los hombres mayores, quienes podían tener dos o tres esposas. Cuando se evangelizó La Batea, los hombres 
polígamos se vieron obligados a separarse de las esposas más recientes ${ }^{17}$. Un rito primordial en la comunidad Eñepá tradicional aplacado por la evangelización es el katyayïnto, que celebra la iniciación de los niños varones quienes visten su primer "guayuco" y adquieren el nombre de adultos. Se trata de una fiesta que dura varios días y que involucra toda la comunidad.

A pesar de estas discontinuidades la forma de nombrar a cada individuo en la comunidad se mantiene según las usanzas Eñepá, lo cual nos conduce a la idea de simultaneidad de cosmovisiones. El otorgamiento del nombre es un aspecto fundamental para entender cómo se concibe el Ser, así como la manera en que se van redefiniendo las diversas etapas de la vida marcadas por rituales de iniciación: desde que son recién nacidos hasta que tienen tres años carecen de nombre propio y se llaman namchá; cuando cumplen cuatro años hasta los nueve son llamados tikon y adquieren un primer nombre provisional que será sustituido por su nombre definitivo en la pubertad. Para las mujeres adultas solo existen cuatro posibles nombres (Achïm, Entyó, Atum, Matë) mientras que para los hombres hay seis posibilidades (Najtën, Puká, Tanë, Winyë, Mañán, Tosé18).

Si bien la forma más "visible" del ritual de iniciación de los niños varones (el katyayïnto o la "puesta del guayuco") fue aplacado durante la evangelización, no sucedió lo mismo con la iniciación femenina, la cual se lleva a cabo aún hoy en la intimidad del círculo familiar de las mujeres. Así, mediante la pintura corporal tuve la oportunidad de conocer este ritual que coexiste aún con las nuevas formas rituales cristianas. Sin embargo, antes de explicar este hecho se requiere una breve explicación acerca de la importancia de la pintura para el cuerpo en esta cultura.

Antes de la evangelización, los rituales Eñepá se caracterizaban por la presencia de una prolífica pintura corporal. Mujeres y niños solían pintar diariamente sus cuerpos enteros y rostros con onoto (E: waché, L: Bixa orellana), mientras que para los rituales el uso de este ungüento rojo se extendía a todos los miembros de la comunidad. El onoto podía aplicarse en estas ocasiones de manera uniforme o con sellos de diversos patrones que se diferenciaban entre sexo, edad y estado espiritual-social. Asimismo, para el uso ritual era sumamente frecuente la pintura negra-azulada de caruto (E: waré, L: Genipa sp.) mezclada con una resina muy aromática conocida popularmente como karaña (E: ayawá, L: Protium heptaphylum), que podía aplicarse tanto en líneas geométricas como por medio de los sellos corporales (E: mapiyó). No obstante, en las últimas dos décadas estas costumbres perecen haber ido desapareciendo progresivamente, aunque según los informantes esto no se debe a la persuasión de MNT sino a que comenzaron a adoptar las usanzas de los criollos (Marisol y Carolina Requena, Vicente Flores, com. personal 2015, 2016).

Sin embargo, con el tiempo comencé a notar algunos elementos que denotaban la persistencia de costumbres previas a la evangelización. En una primera ocasión, justo en el momento de partir de regreso a Caracas, se acercó a despedirse una niña que tenía la cara pintada con puntos negros de karaña alrededor de sus ojos, creando una suerte de antifaz. En ese momento no pude obtener respuesta de quién la había pintado, ni por qué, ni qué significaba esa pintura; sin embargo, observando diversos registros fotográficos de hace unas dos o tres décadas, pude observar que las madres solían pintar de esta manera a sus hijas pequeñas (por ejemplo en Valles 1992 [sin paginación] o Henley 1982:88).

Finalmente, mi percepción respecto de los ritos de iniciación cambió definitivamente una tarde en la que varias niñas entraron a la churuata donde me hospedaba y observé que una adolescente de doce años tenía las piernas pintadas con puntos negros (Figura 3). Le pregunté si había tenido su primera menstruación recientemente, a lo que respondió que sí. A continuación explicó que su mamá y su abuela la habían pintado con karaña. Con este hecho pude percatarme que continuaba existiendo una manera de ver y ritualizar el mundo perteneciente a prácticas anteriores a la evangelización. Aunque fluyen de manera mucho menos evidente y con una clara intención de mantenerla velada a los forasteros, para los Eñepá no presentan una contradicción con el mundo evangelizado. Así podríamos entender el hecho de que la misma niña que tenía las piernas pintadas asistía tranquilamente con su familia a los servicios religiosos evangélicos.

Cabe destacar también que la presencia del onoto y de sellos corporales es constante a pesar de que digan reiteradamente que ya no los usan. La familia Requena me ha regalado en varias ocasiones sellos corporales tallados por ellos. Además, tienen siempre en sus hogares pasta de onoto lista para usar. Asimismo, en la mayoría 


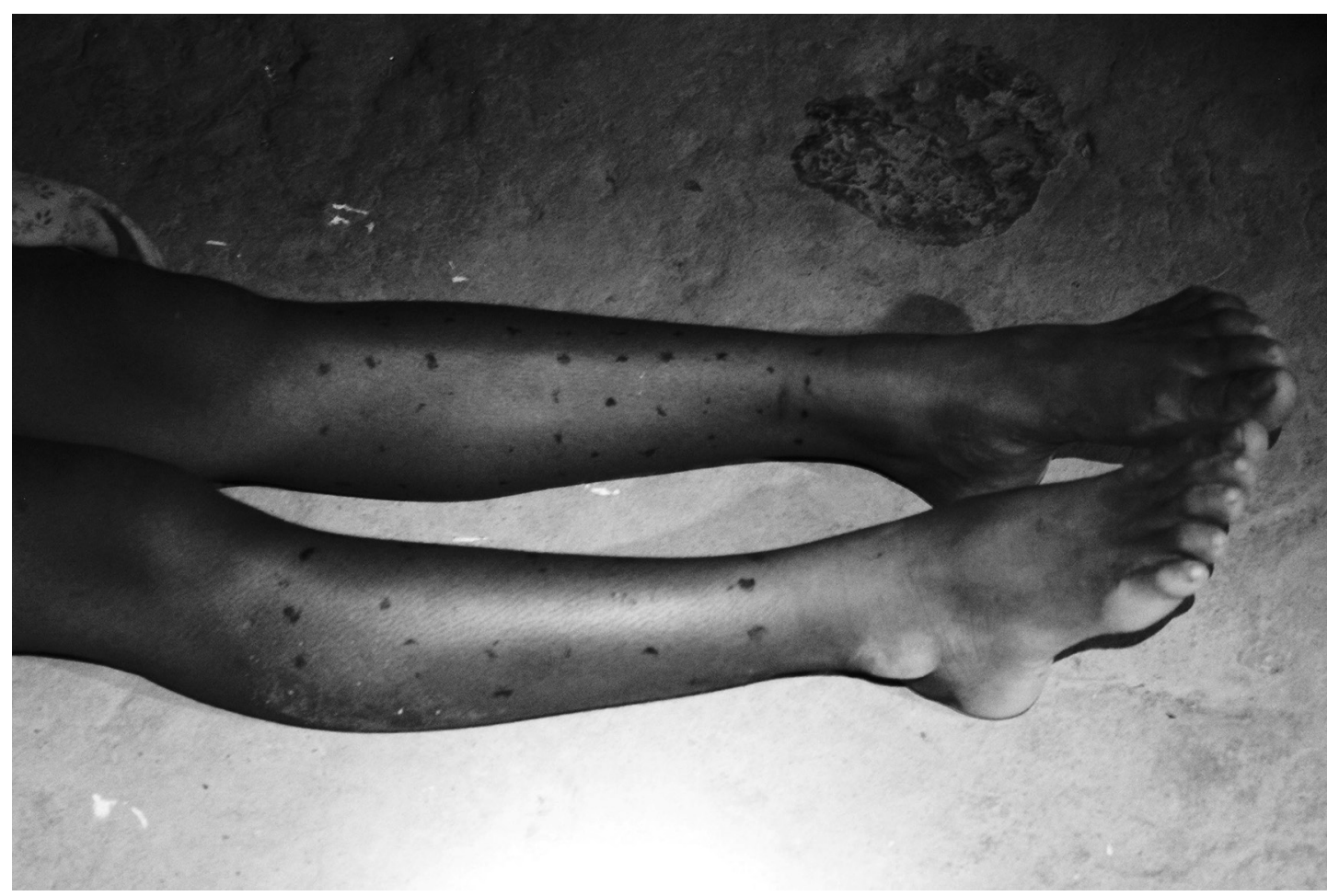

Figura 3. Niña de 12 años (2015) muestra sus piernas pintadas con karaña (fotografía de la autora). 12-year-old girl (2015) shows her legs painted with karaña (photography by the author).

de las casas secan la semilla de onoto, aunque explican que solo lo usan para teñir los guayucos y las telas de las hamacas.

La pervivencia de los conocimientos ancestrales y su práctica en la cotidianidad también se evidencia en los conocimientos de la naturaleza, que responden a un orden de pensamiento previo a la evangelización. Así, hemos podido notar que a pesar de la eliminación de los principales rituales chamánicos de curación, los adultos y ancianos aún tienen un vastísimo conocimiento botánico que les permite elaborar varios ungüentos y medicamentos tradicionales. Estos consisten básicamente en vomitivos, antidiarreicos o antipiréticos, con el que "expulsan" muchas enfermedades, y ungüentos para dolores o para evitar las picadas de mosquitos. La pintura con karaña tiene también propiedades medicinales, por lo que muchas personas -sobre todo las mujeres- la usan para dibujar puntitos en aquellas zonas del cuerpo afectadas por dolencias como el reumatismo.

Otras prácticas tradicionales se pueden observar en actividades cotidianas como la cacería, para la cual, aparte de usar escopetas modernas, muchos prefieren tecnologías ancestrales que están íntimamente imbricadas con la ritualidad y la ontología amazónica. El señor José Moreno, por ejemplo, es uno de los hombres más ancianos del pueblo y aún va al bosque a buscar las plantas con las que se hace el curare, veneno con el que se bañan las puntas de los dardos de las cerbatanas (Figura 4). El proceso de elaboración tanto de la cerbatana como del veneno es sumamente complicado e implica una serie de conocimientos y restricciones rituales para obtener el permiso de los "dueños" de las plantas de las cuales se extrae la materia prima. Cabe destacar también que la cacería aún sigue ciertas normas rituales de antaño, como por ejemplo, la de ser una actividad exclusiva de los hombres. Según nos explicó Juan Requena (com. personal 2014), "antes" los hombres se pintaban con pintura negra con karaña para ir de cacería; si bien comentó que ya no lo hacen, no he podido corroborarlo.

Otras actividades cotidianas también siguen una estricta división según género, lo cual está relacionado con una razón de ser sagrada y con una manera específica de concebir a los individuos y sus roles simbólicos y sociales. Así, la cestería 


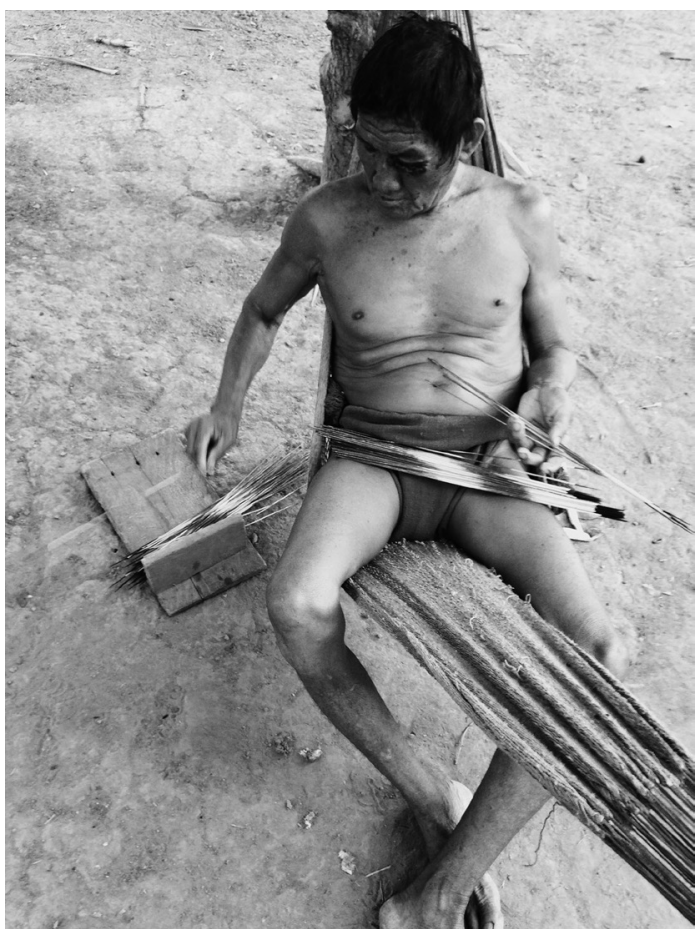

Figura 4. El señor José Moreno revisa los dardos para su cerbatana antes de untarlos con curare (fotografía de la autora). Mr. José Moreno inspects the darts of his blowgun before smearing them with curare (photography by the author).

es actividad exclusiva de los hombres, ya que sus fibras deben ser extraídas del ámbito indomesticado y potencialmente peligroso de la selva, sirviendo así como objetos-puente entre lo domesticado y lo indómito. Por el contrario, una vez que el espacio de la cosecha (el conuco) es talado y quemado por los hombres, el proceso de domesticación y cocción de los alimentos queda en manos de las mujeres.

Los mismos rituales cristianos y formas de entender el cristianismo han adquirido en La Batea una forma sui generis. En los servicios religiosos participan el pastor principal, los ayudantes, que son los hombres que conocen mejor el Evangelio, y los músicos. Cada domingo realizan dos veces al día largos servicios religiosos que pueden prolongarse hasta cinco horas. En estos van intercalándose canciones y sermones recitados enteramente en Eñepá que se encuentran a cargo de varios hombres. La asistencia al servicio acontece de manera espontánea y tanto niños, mujeres y hombres -incluyendo los pastores y músicos- entran y salen a gusto durante el servicio.
El orden al interno de la iglesia es más estricto y se divide claramente entre los hombres que se sientan en taburetes y sillas del lado derecho de la iglesia y las mujeres que se sientan en el suelo del lado izquierdo; mientras que los niños corretean libremente por la iglesia y se sientan donde les place. Las canciones del servicio religioso son composiciones musicales que mezclan diversos estilos como la bachata, la cumbia y el aguinaldo, acompañadas por una o dos guitarras (que pueden ser eléctricas o acústicas) y un teclado eléctrico. La musicalización está compuesta esencialmente por canciones simples, de ritmo monótono, cuyos coros son acompañados ocasionalmente por las mujeres.

Algunos aspectos que refieren a la tonalidad y las dinámicas que acontecen en estos servicios se asemejan mucho a las reuniones del consejo de hombres, realizadas periódicamente en el pueblo para discutir los asuntos económicos y sociales. En estas impera, al igual que en el servicio religioso, la voz monótona de un locutor seguida por esporádicas y pausadas intervenciones de los hombres y el acompañamiento callado de las mujeres, en una clara posición resguardada y desde el suelo.

Para dar fin a este apartado cabe destacar que según Juan Requena los motivos del progresivo abandono de algunas costumbres rituales se deben más a la criollización que a la evangelización (Juan Requena, com. personal 2016). Porfió en aclarar que costumbres como la pintura corporal, los atavíos y la música ancestrales no habían sido abandonadas por persuasión de los misioneros de MNT, a quienes incluso les gustaban estas tradiciones y solicitaron que tocaran sus flautas en los servicios religiosos. No obstante, los Eñepá prefirieron utilizar la música y los instrumentos procedentes del mundo "criollo". Entendemos con ello que no hizo falta que los misioneros prohibieran o desestimaran las costumbres Eñepá, ya que al estar íntimamente imbricadas con la cosmovisión y los rituales anteriores se volvieron incompatibles con las nuevas creencias y rituales. Se ejemplifica así nuevamente cómo ambas formas de entender el mundo prefieren no "mezclarse", aunque sí logran coexistir en alternancia.

\section{Conclusiones}

Este estudio puede verse como un esbozo que reúne las primeras descripciones e impresiones obtenidas a partir del período de trabajo en terreno 
en la comunidad Eñepá de La Batea, el cual apenas constituye el inicio de lo que se espera que sea un fructífero campo de estudio. Sin embargo, considero relevante que en unos pocos meses de trabajo de campo, con las limitaciones lingüísticas y de medios de comunicación, se haya podido desvelar tanta información acerca de la presencia de dos cosmovisiones en esta cultura. Con esto quiero decir que, estudiado desde el enfoque perspectivista propuesto por Viveiros de Castro (2002) y como ha podido corroborar por su parte Vilaça (2016), el proceso de evangelización por MNT ha complejizado la visión de mundo de los Eñepá, sin significar por ello una total pérdida o sustitución de costumbres pasadas.

Los recientes procesos de cambio hacia una forma de vida y unas creencias religiosas procedentes del mundo "moderno" y evangélico han sido fenómenos que han afectado el cauce de estas tradiciones, mas no las transformaron por completo (Figura 5). Más bien parecen haber congeniado con la forma de entender el mundo tradicional. A lo largo de las visitas a La Batea fue haciéndose evidente que el encuentro con los
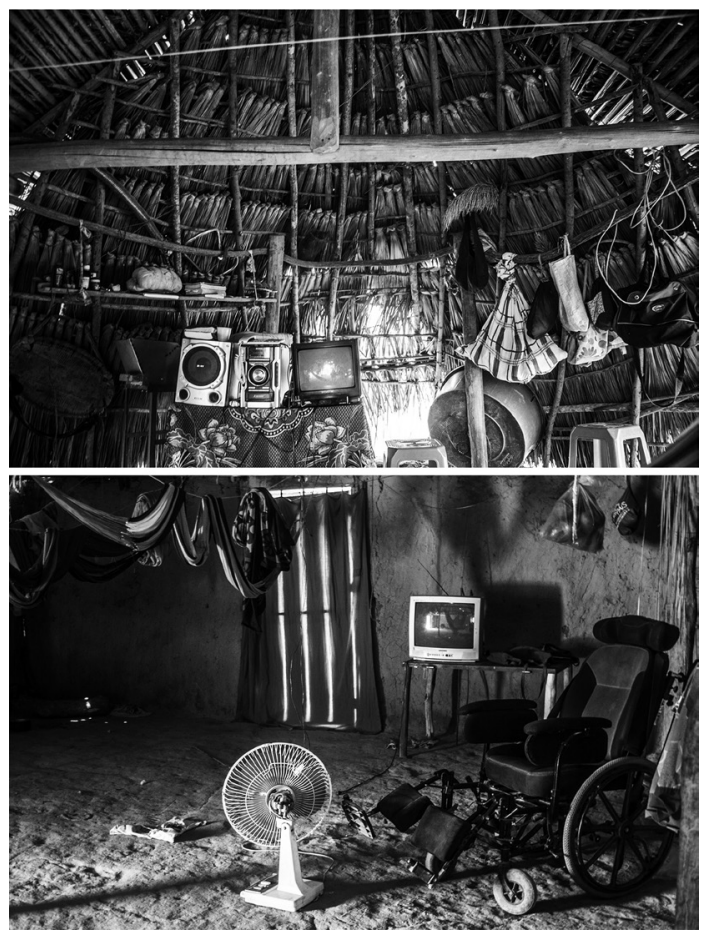

Figura 5. Mundos "moderno" y "tradicional" en convivencia (fotografía de la autora).

Coexistence of the "modern" and "traditional" worlds (photography by the author). evangelizadores no tuvo el efecto de suplantación de credos y cambio de costumbres que tenía intencionalmente.

Así, observamos un discurrir paralelo de dos cosmovisiones que no se anulan, sino se alternan y toman su espacio separado en la vida cotidiana: de esta manera, el mundo del Dios cristiano rige por ejemplo las dinámicas morales y sociales dentro de la comunidad, mientras que la cosmovisión amazónica pervive en las relaciones con el mundo de la naturaleza, la relación con la selva, el río, los animales, así como las prácticas tradicionales como la cestería, la siembra del conuco, la cacería y la pesca. Asimismo, comprobamos que la cosmovisión amazónica no cambió como tal; únicamente lo hizo el mito, en la medida en que entraron nuevos héroes culturales y narrativas introducidas por la evangelización. Sin duda, y en concordancia con el caso Warí estudiado por Vilaça, MNT introdujo nuevas categorías morales, como las nociones de culpa, pecado y castigo, diferentes a las tradicionales (Vilaça 2016:194). Sin embargo, otros elementos sustanciales como la percepción del mundo natural y sobrenatural continúa manteniéndose propiamente Eñepá.

El punto central de esta investigación consistió en averiguar si esta forma multinaturalista y perspectivista coexiste con la creencia cristiana. Efectivamente, es posible ver cómo la relación con los espacios de la naturaleza, los animales y dominios externos a los territorios Eñepá demuestran que aún existe una relación multinaturalista con el reino natural y espiritual, en la medida en que los animales y las plantas poseen "dueños" con quienes hay que "negociar" para interactuar con ellos. Y así, el Dios cristiano y el concepto de la Trinidad, que desplazaron en cierta medida la imagen de Mareaoka y los mitos de creación ancestrales, funcionan como categorías que conciernen sobre todo el mundo moral, pero no el natural o no humano, donde aún rige la ontología antigua. Del mismo modo, el desarrollo del mismo individuo y la relación con su comunidad tampoco desaparece en la medida en que persisten costumbres como la manera de clasificar al ser humano según diversas etapas vitales (desde la lactancia hasta la adultez). Por último, destacamos que muchos de sus conocimientos y prácticas nunca dejaron de existir en el seno de la intimidad, pero fueron ocultados y guardados con recelo ante la cara del criollo o extranjero para protegerlos de ulteriores proscripciones o críticas. 
Así, el mundo Eñepá preevangelizado está lejos de extinguirse, como temía Dumont (1972), quien creía estar presenciando hace más de 40 años la última generación que conocía estas tradiciones. Se trata en cambio de conocimientos palpitantes que continúan perviviendo en una resistencia silente y una adaptación constante las diversas coyunturas históricas y sociales.

Agradecimientos: Este artículo fue realizado en el marco del proyecto postdoctoral FONDECYT 2015 No. 3150061. Agradezco profundamente al Dr. José Luis Martínez de la Universidad de Chile por sus valiosos consejos y correcciones. Este trabajo no hubiera sido posible sin el apoyo del Dr. Bernardo Urbani, la Dra. Eglée Zent y la
Dra. Érika Wagner del Instituto Venezolano de Investigaciones Científicas y la Dra. Marie Claude Mattei-Muller. Extiendo mi agradecimiento a Luis García Briceño por ayudarme con la bibliografía y a Miquel Figueras por su orientación respecto de la actualidad Eñepá y haberme introducido a la comunidad de La Batea; así como a quienes me acompañaron en visitas a esta población: Marco Caputo, Valeska Merizalde y Katherine Román. Se agradece especialmente a los evaluadores anónimos que hicieron fundamentales anotaciones y correcciones sobre el texto. Este artículo fue realizado para y gracias al aporte de toda la comunidad de La Batea; su cacique Roberto Moreno, su capitán Vicente Flores y en especial a la familia Requena, a quien dedico este trabajo.

\section{Referencias Citadas}

Civrieux, M. 1976. Los Caribes y la Conquista de la Guayana Española. Universidad Católica Andrés Bello, Caracas.

Consejo Nacional Electoral, Constitución de la República Bolivariana de Venezuela 2011. http://www.cne.gov.ve/web/ normativa_electoral/constitucion/indice.php (13 septiembre 2016).

Corradini, H. 2002. Panare. Grupo La Galaxia, Caracas.

Corradini, H. 1981. ¡Los indios Panare asesinaron a Jesucristo! En El Caso Nuevas Tribus, editado por E. Monsonyi, M. Acosta Saignes, R. Domínguez, N. Arvelo, H. Corradini, G. Marrero, W. Coppens, A. Luzardo, S. Rivas, A. Montiel, R. Castillo y S. Gimenes, pp. 105-118. Editorial Ateneo de Caracas, Caracas.

Dumont, J.P. 1971. Compte rendu de mission chez les Indiens Panare. L'Homme 11(1):83-88.

Dumont, J.P. 1972. Under the Rainbow. A Structural Analysis of the Concepts of Nature, Culture and Supernature among the Panare Indians. University of Texas, Austin.

Gilij, S. 1965 [1782]. Ensayo de Historia Americana Tomos I, II y III. Academia Nacional de la Historia, Caracas.

Gumilla, J. 1745. El Orinoco Ilustrado y defendido. Aguilar, Madrid.

Henley, P. 1982. The Panare. Tradition and Change on the Amazonian Frontier. Yale University Press, New Haven.

Henley, P. 2011. Los E’ñepá (Panare). En Los Aborígenes de Venezuela, Volumen III, editado por W. Coppens, 585-693. Fundación La Salle, Caracas.

Instituto Nacional de Estadística, Gobierno Bolivariano de Venezuela. http://www.ine.gob.ve/documentos/Demografia/ CensodePoblacionyVivienda/pdf/ResultadosBasicos.pdf (13 septiembre 2016).

Luzardo, A. 1981. Nuevas Tribus - Etnocidio y violaciones de la soberanía nacional. En El Caso Nuevas Tribus, editado por E. Monsonyi, M. Acosta Saignes, R. Domínguez, N. Arvelo, H. Corradini, G. Marrero, W. Coppens, A. Luzardo, S. Rivas, A. Montiel, R. Castillo y S. Gimenes, pp. 105-118. Editorial Ateneo de Caracas, Caracas.

Mattei-Muller, M.C. 1992. Yoroko: Confidencias de un Chamán Panare. Armitano, Caracas.
Mattei-Muller, M.C. 1994. Diccionario Eñepá-Español. Comisión Nacional Quinto Centenario, Caracas.

Mattei-Muller, M.C. y P. Henley 1978. Wapa. La Comercialización de la Artesanía Indígena y su Innovación Artística: el Caso de la Cestería Panare. La Huella/Tecnocolor, Caracas.

Misión Nuevas Tribus. https://usa.ntm.org/about/our-heritage (13 septiembre 2016).

Merleau-Ponty, M. 1994. Fenomenología de la Percepción. Planeta, Buenos Aires.

Monsonyi, E., M. Acosta Saignes, R. Domínguez, N. Arvelo, H. Corradini, G. Marrero, W. Coppens, A. Luzardo, S. Rivas, A. Montiel, R. Castillo y S. Gimenes 1981. El Caso Nuevas Tribus. Editorial Ateneo de Caracas, Caracas.

Price, J. y J. Price 1972. Got any rivers? Brown Gold 30(4):4-10 Price, J. y J. Price 1977. Panare breakthrough. Brown Gold 35(1)10.

Quatra, M.M. 2009. El Proceso de iniciación chamánica en la comunidad Eñepa de San José de Kayamá. Antropológica LII(110):35-87.

Valles, C. 1992. Signos en la Piel. La Pintura Corporal en la Cultura Panare. Colección V Centenario de Encuentro entre Dos Mundos, Caracas.

Vilaça, A. 2015. Dividualism and individualism in indigenous Christianity. Hau: Journal of Ethnographic Theory 5(1):197-225.

Vilaça, A. 2016. Praying and Preying. Christianity in Indigenous Amazonia. University of California Press, Oakland.

Villalón, M.E. 1979. Evangelistas norteamericanos siembran miedo entre los Panare. Hacia la Autogestión Indígena 2(1-2):1-4.

Villalón, M.E. 2007. E’ñapa. En Salud Indígena en Venezuela, Vol 2, editado por G. Freire y A. Tillett, pp. 13-73. Ministerio del Poder Popular para la Salud, Caracas.

Viveiros de Castro, E. 2002. A Inconstância da Alma Selvagem, e Outros Ensaios de Antropologia. Cosac \& Naify, São Paulo.

Wilbert, J. 1959. Aspectos sociales de la cultura Panare. Antropológica 7:47-62. 


\section{Notas}

1 La Batea es accesible con automóvil todo el año, mientras que otros pueblos cercanos como Colorado o Caño Amarillo son inaccesibles durante la estación de lluvia.

2 Censo indígena 2011, http://www.ine.gov.ve/documentos/ Demografia/CensodePoblaciony Vivienda/pdf/ ResultadosBasicos.pdf (revisado 20 de enero de 2017).

3 Película: "A Clearing in the Jungle", Disappearing World Series, UK. $52 \mathrm{~min}$.

4 Película: "Reclaiming the Forest", UK, 39 min.

5 Puede leerse con detalle la doctrina de la IFCA (Independent Fundamentalist Churches of America) en http://www.ifca. org/ (revisado el 20 de enero de 2017).

6 Capítulo VIII, Ley de los pueblos indígenas, Artículos 119, $121,123$.

7 Ley de Misiones 1915 en docs.venezuela.justicia.com/ federales/leyes/ley-de-misiones.pdf (consultado el 11 de septiembre de 2016).

8 Se trata de pequeños centros proporcionados por el Estado donde se puede dar asistencia médica básica a los integrantes de las comunidades indígenas. José realizó unos cursos básicos de enfermería y medicina primaria en una ciudad cercana (Caicara del Orinoco).

9 Los nombres utilizados para referirme a los informantes son aquellos “criollos”, ya que sus nombres Eñepá no son desvelados a desconocidos criollos o extranjeros.

10 Video promocional de Misión Nuevas Tribus: Unreachable, https://www.youtube.com/watch?v=JixPmt4iwLE (consultado 17 de septiembre de 2016)

11 Tal es el caso de la familia Moreno: el señor José Moreno rehúsa ir a la iglesia, pero su esposa sí asiste. Sin embargo, al preguntarle al señor Moreno si era evangélico respondía -si bien con cierto escepticismo-que sí. El señor Moreno es una de las pocas personas que aún posee una flauta tradicional, pero aún no ha estado dispuesto a mostrármela.
12 Existe una discrepancia entre el nombre del pueblo escrito por la iglesia evangélica (Las Bateas) y el nombre oficial, registrado por el gobierno (La Batea).

13 Como indica Viveiros de Castro, el perspectivismo es aplicable a algunos animales, como por ejemplo, grandes predadores (el jaguar) o animales de presa (el báquiro), algunas aves y peces. La mayoría de estos se encuentran en los relatos míticos. Generalmente estas relaciones existen con animales con los que se mantiene una relación de predador o presa así como aquellos que poseen cualidades constitutivas similares a los humanos (Viveiros de Castro 2002:353).

14 Con el término "normal" se refiere Viveiros de Castro a una condición sensible ordinaria, al contrario de la sensibilidad adquirida por ejemplo por los chamanes en sus estados de trance, en los que pueden "ver", "sentir" e incluso convertirse en otros seres espirituales que, en principio, son invisibles (Viveiros de Castro 2002:227-229).

15 El mito de creación actual que relatan los Eñepá corresponde al Génesis cristiano. Personas como José Moreno, quien aún recuerda los mitos del pasado, ha prometido relatármelos en cuanto domine mejor su idioma (conversaciones con José Moreno, 2015 y 2016).

16 Es interesante notar que esta versión de Amana coincide con la que recogió Mattei-Muller (1992) en Caño Amarillo (que pertenece a la misma región de La Batea) y difiere, en cambio, de la versión recogida por Quarta (2002) en Kayamá (muy alejada de La Batea, donde incluso el acento y algunas palabras eñepá difieren).

17 Tal fue el caso de José Moreno, cuya segunda esposa fue obligada a trasladarse a otro poblado (Marisol y Carolina Requena, comunicación personal 2016).

18 No se han registrado motivos míticos sobre los orígenes de estos nombres; solo sabemos que se escogen según la apariencia física o carácter del individuo. 